\title{
Genomic heritability and genome-wide association analysis of anti-Müllerian hormone in Holstein dairy heifers
}

\author{
M. Y. Nawaz, ${ }^{*}$ F. Jimenez-Krassel, ${ }^{*}$ J. P. Steibel, ${ }^{*}$ Y. Lu, ${ }^{*}$ A. Baktula,† N. Vukasinovic,† L. Neuder,† \\ J. L. H. Ireland, ${ }^{*}$ J. J. Ireland, ${ }^{*}$ and R. J. Tempelman ${ }^{* 1}$ \\ *Department of Animal Science, Michigan State University, East Lansing 48823 \\ †Zoetis Inclusions, Kalamazoo, Ml 49007 \\ ‡Green Meadow Dairy Farm, Elsie, MI 48831
}

\section{ABSTRACT}

Anti-Müllerian hormone (AMH) is an ovarian growth factor that plays an important role in regulation of ovarian follicle growth. The objectives of this study were to estimate the genomic heritability of $\mathrm{AMH}$ and identify genomic regions associated with AMH production in a genome-wide association (GWA) analysis. Concentrations of AMH were determined in 2,905 dairy Holstein heifers genotyped using the Zoetis medium density panel (Zoetis Inclusions, Kalamazoo, MI) with 54,519 single nucleotide polymorphism (SNP) markers remaining after standard genotype quality control edits. A linear mixed model was used to model the random effects of sampling day and genomics on the logarithm of AMH. The genomic heritability ( \pm standard error of the mean) of AMH was estimated to be $0.36 \pm 0.03$. Our GWA analysis inferred significant associations between AMH and 11 SNP markers on chromosome 11 and 1 SNP marker on chromosome 20. Annotated genes with significant associations were identified using the Ensembl genome database (version 88) of the cow genome (version UMD 3.1; https://www.ensembl.org/ biomart). Gene set enrichment analysis revealed that 2 gene ontology (GO) terms were significantly enriched in the list of candidate genes: G-protein coupled receptor signaling pathway (GO:0007186) and the detection of chemical stimulus involved in sensory perception (GO:0050907). The estimated high heritability and previously established associations between AMH and ovarian follicular reserve, fertility, longevity, and superovulatory response in cattle implies that $\mathrm{AMH}$ could be used as a biomarker for genetic improvement of reproductive potential.

Key words: genome-wide association, heritability, reproduction

\footnotetext{
Received March 22, 2018.

Accepted May 16, 2018.

${ }^{1}$ Corresponding author: tempelma@msu.edu
}

\section{INTRODUCTION}

The rate of genetic improvement for reproductive performance in dairy cattle is relatively slow (García-Ruiz et al., 2016), partly because heritability estimates of conventional reproductive traits of dairy cattle are low, typically ranging from 0.02 to 0.17 (Berry et al., 2014). Reliable biomarkers highly correlated with reproductive performance, expressed early in life, and moderately to highly heritable have not yet been discovered. Such a discovery would be useful in identifying cattle with superior reproductive potential and designing breeding programs for faster genetic gain in reproductive efficiency to enhance profitability of the dairy industry.

Anti-Müllerian hormone (AMH) has been proposed as an important biomarker of reproductive potential of cattle. It is a growth factor produced by granulosa cells of ovarian follicles and Sertoli cells of testes, and it was first discovered to play an important role in sex differentiation during embryo development (Baarends et al., 1994; Allard et al., 2000). In adults, however, AMH is known to regulate ovarian follicle growth (Tiftik et al., 2016) as it prevents initial recruitment and the premature depletion of the follicular population in the ovary (Durlinger et al., 1999, 2002). Anti-Müllerian hormone may also inhibit FSH-induced follicular growth because it reduces the sensitivity of follicles to FSH treatments (Durlinger et al., 2001). Consequently, AMH may play a role in determining which follicles undergo selection and grow, and which follicles undergo atresia.

Our research group has shown that circulating AMH concentration is positively correlated with ovary size, number of antral follicles growing during follicular waves, and size of the ovarian reserve (total number of morphologically healthy oocytes in ovaries; Ireland et al., 2008). Anti-Müllerian hormone has been determined to predict ovarian progesterone (Ireland et al., 2009), androgen production (Mossa et al., 2010), herd longevity (Jimenez-Krassel et al., 2015), maintenance of pregnancy, and pregnancy rate in dairy cows bred on estrus (Ribeiro et al., 2014). It is also positively cor- 
related with response to superovulation (Ireland et al., 2007 ) and embryo production in dairy cattle (Monniaux et al., 2010; Guerreiro et al., 2014). Although highly variable among individuals, serum AMH concentration is highly repeatable within animals and not affected by the stage of estrous cycle (Ireland et al., 2008, 2011). Thus, AMH concentration is a reliable phenotypic marker, not only for size of the ovarian reserve, ovarian function, and response to superovulation, but also for fertility and herd longevity. Taken together, these findings imply that AMH may be useful for identification and subsequent genetic selection of cattle with superior reproductive potential, provided that serum AMH is at least moderately heritable.

The first objective of the present study was to estimate the genomic heritability of AMH. Our second objective was to use genome-wide association (GWA) analyses to help identify genomic regions associated with AMH using a medium-density SNP genotype panel.

\section{MATERIALS AND METHODS}

All experiments involving cattle were approved by the Institutional Animal Care and Use Committee at Michigan State University. Holstein heifers $(\mathrm{n}=3,252$, 11-15 mo old, located at Green Meadow Farms Inc., Elsie, MI) were each subjected to 2 intramuscular injections of $\mathrm{PGF}_{2 \alpha}$ spaced $11 \mathrm{~d}$ apart to synchronize estrous cycles. Heifers were synchronized in groups of 95 to 124 heifers once or twice a month for a total of 29 groups or sampling dates. At $96 \mathrm{~h}$ after the last $\mathrm{PGF}_{2 \alpha}$ injection, a single tail-vein blood sample was taken from each heifer to measure serum AMH concentration. Blood samples were taken beginning on April 14, 2014 (sampling date 1) and ending on December 4, 2015 (sampling date 29). Follicle hair samples were also collected at these sampling dates for genotypic analyses. Freemartins ( $\mathrm{n}=$ 144) were not included in the statistical analyses.

\section{AMH Assay}

The commercially available ELISA kit for bovine AMH (MiniTube of America, Verona, WI) was used to measure serum AMH concentrations in duplicate $20-\mu \mathrm{L}$ serum samples in cattle per kit instructions. The 2-site AMH assay has been validated (Ireland et al., 2008) for use in cattle and does not cross-react with other members of the transforming growth factor $\beta$ (TGF $\beta$ ) superfamily including TGF $\beta$, bone morphogenic factor-4, inhibin, or activin (Kevenaar et al., 2006). The interassay coefficients of variation for 105 assays for low, intermediate, and high quality controls were 17,
16 , and $20 \%$, respectively. In addition, to evaluate potential AMH degradation during storage, serum AMH concentrations for 5 heifers in the study after $\sim 1$ mo storage at $-80^{\circ} \mathrm{C}$ were determined to be $75,55,1,117$, 436 , and $208 \mathrm{pg} / \mathrm{mL}$. When samples from these same individuals were assayed $\sim 12 \mathrm{mo}$ after storage at $-80^{\circ} \mathrm{C}$, AMH concentrations were 59, 48, 1,227, 435, and 191 $\mathrm{pg} / \mathrm{mL}$, respectively. These results implied that $\mathrm{AMH}$ is relatively stable during long-term storage.

\section{Genotyping and Pedigree Information}

A total of 2,939 Holstein heifers were genotyped for SNP markers using a Zoetis proprietary mediumdensity SNP panel (Zoetis Genetics, Kalamazoo, MI). Four-generation pedigree information of these animals was also retrieved to construct an additive relationship matrix. The genotypes were imputed to the standard USDA 60,671 bovine SNP set (Wiggans et al., 2016) by the USDA Animal Genomics and Improvement Laboratory (Beltsville, MD). Animal genotypes and SNP markers were retained for analysis only if they fulfilled the following criteria: missing values $<20 \%$, minor allele frequency $(\mathrm{MAF})>0.05$, and pairwise linkage disequilibrium (LD) value of $\mathrm{r}^{2}<0.95$. The final data set used for statistical analysis after data editing included phenotypes and genotypes for $m=54,519$ SNP markers on each of 2,905 cows and their 4-generation pedigree information.

\section{Statistical Analysis}

A linear mixed model was used to model the random effects of sampling day and genomics on the logarithm of AMH to estimate the genetic, sampling day, and residual variance components. The linear model used for analysis is provided in Equation [1]:

$$
y_{i j}=\mu+d_{i}+a_{j}+e_{i j}
$$

where $y_{i j}$ is the AMH phenotype taken on day $i$ on heifer $j ; \mu$ is the overall mean; $d_{i} \sim \operatorname{NIID}\left(\mathbf{0}, \sigma_{d}^{2}\right)$ is the random effect of the date of sample collection, $i=1,2$, ..., 29, with $N I I D=$ normally, identically, and independently distributed; and $e_{i j} \sim \operatorname{NIID}\left(\mathbf{0}, \sigma_{e}^{2}\right)$ is the residual term for the record on animal $j$ taken on date $i$. Furthermore, $a_{j}$ is the genomic merit of animal $j, j=1$, $2, \ldots, 2,905$, with $\mathbf{a}=\left\{a_{j}\right\} \sim N\left(0, \mathbf{A} \sigma_{a}^{2}\right)$. Here, $\sigma_{d}^{2}$ refers to variance of the effects of date of sample collection, $\sigma_{a}^{2}$ is the additive genetic variance, and $\sigma_{e}^{2}$ is the residual variance.For pedigree-based heritability estimation, A was the matrix of additive genetic relation- 
ships between animals. To estimate genomic heritability, $\mathbf{A}$ was replaced by $\mathbf{G}=\mathbf{Z} \mathbf{Z}^{\prime}$, being the genomic relationship matrix for which elements $\left(z_{j k}\right)$ of $\mathbf{Z}$ are characterized as in Equation [2]:

$$
z_{j k}=\frac{m_{j k}-2 p_{k}}{\sqrt{\sum_{1}^{m} 2 p_{k}\left(1-p_{k}\right)}} .
$$

In Equation [2], $m_{j k}$ indicates the number of copies (0, 1 , or 2) of the reference allele on SNP marker $k$ for animal $j$, whereas $p_{k}$ denotes the allelic frequency of the reference allele for SNP marker $k$. Restricted maximum likelihood was used to provide estimates of $\sigma_{a}^{2}, \sigma_{d}^{2}$, and $\sigma_{e}^{2}$. Heritability was determined as taking the proportion of total phenotypic variation $\left(\sigma_{a}^{2}+\sigma_{d}^{2}+\sigma_{e}^{2}\right)$ that was due to genomics $\left(\sigma_{a}^{2}\right)$.

The reliability $r_{j}^{2}$ of $\hat{a}_{j}$, the genomic estimated breeding value (GEBV) for animal $j$, with GEBV being synonymous with the BLUP of $a_{j}$, was determined as in Equation [3] (Van Vleck, 1993):

$$
r_{j}^{2}=\frac{\hat{\sigma}_{a}^{2}-c_{j j}}{\hat{\sigma}_{a}^{2}},
$$

where $\hat{\sigma}_{a}^{2}$ is the REML estimate of $\sigma_{a}^{2}$ under the genomic model (i.e., using $\mathbf{G}$ ) and $c_{j j}=\operatorname{var}\left(a_{j}-\hat{a}_{j}\right)$ refers to the prediction error variance for $\hat{a}_{j}$. The GEBV for all animals, that is, $\hat{\mathbf{a}}=\left\{\hat{a}_{j}\right\}$, were linearly transformed to the estimated marker effects $\hat{\mathrm{g}}=\left\{\hat{g}_{k}\right\}$, as demonstrated by Gualdrón Duarte et al. (2014) using Equation [4]:

$$
\hat{\mathbf{g}}=\mathbf{Z}^{\prime} \mathbf{G}^{-1} \hat{\mathbf{a}} .
$$

The variance of $\hat{\mathrm{g}}$ can be determined using classical mixed model theory, as also illustrated by Gualdrón Duarte et al. (2014), using Equation [5]:

$$
\operatorname{Var}(\hat{\mathbf{g}})=\mathbf{Z}^{\prime} \mathbf{G}^{-1} \mathbf{Z} \sigma_{a}^{2}-\mathbf{Z}^{\prime} \mathbf{G}^{-1} \mathbf{C}^{a a} \mathbf{G}^{-1} \mathbf{Z}
$$

where $\mathbf{C}^{a a}=\operatorname{var}(\mathbf{a}-\hat{\mathbf{a}})$ is the prediction error covariance matrix of all GEBV; that is, $c_{j j}$ is diagonal element $j$ of $\mathbf{C}^{a a}$. Using again Gualdrón Duarte et al. (2014), the $z$-test statistic for testing the null hypothesis, $\mathrm{H}_{0}: g_{j}=$ $0, j=1,2, \ldots, m$ can be specified as in Equation [6]:

$$
z_{j}=\frac{\hat{g}_{j}}{\sqrt{ } \operatorname{Var}\left(\hat{g}_{j}\right)} .
$$

The corresponding $P$-value for the test statistic in Equation [6] is provided in Equation [7]:

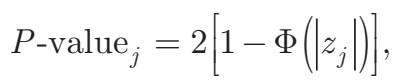

where $\Phi$ denotes the standard normal cumulative distribution function. $P$-values were converted to $q$-values (Storey and Tibshirani, 2003) to declare any SNP marker associations with AMH as significant based on a false discovery rate $(\mathbf{F D R})$ of $5 \%$ (i.e., $q$-value $<0.05$ ).

\section{Number of QTL per Peak}

To infer the number of QTL per region containing a peak (i.e., a $q$-value $<0.05$ ), we refitted the linear mixed model in Equation [1], this time treating the most significant or peak SNP marker as fixed (Casiró et al., 2017). The model thus used was as in Equation [8]:

$$
y_{i j}=\mu+\beta_{\text {peak }} g_{\text {peak }, j}+d_{i}+a_{j}+e_{i j},
$$

where all the terms in Equation [8] are as described in Equation [1] except that $\beta_{\text {peak }}$ denotes the partial regression of $y_{i j}$ on the SNP genotype $g_{p e a k, j}$ at the SNP marker having the smallest $q$-value $<0.05$ on a particular chromosome. If, after fitting $\beta_{\text {peak }}$, all other SNP markers on that same chromosome do not exhibit a significant association (i.e., $q$-value $>0.05$ ), this would be suggestive of no evidence of multiple QTL peaks within the corresponding genomic region (Casiró et al., 2017).

\section{Confidence Interval of the QTL Peak}

We used a cross validation strategy to estimate the 99\% CI for the QTL peak position as proposed by Hayes (2013) and used by Casiró et al. (2017). In this method, we first conducted the GWA as described above to obtain the physical position $(\hat{x})$ of the most significant SNP marker with $q$-value $<0.05$ on a particular chromosome. We then randomly divided the data set into 2 halves (1 and 2) for a particular split $l$, conducting an independent GWA analysis on each half to determine the physical positions $\left(\hat{x}_{1 l}\right.$ and $\hat{x}_{2 l}$, respectively) from both analyses for the most significant SNP marker on that same chromosome. For that same split, we then computed the difference $\left(\hat{h}_{l}=\hat{x}_{1 l}-\hat{x}_{2 l}\right)$ in the distance between these 2 inferred peaks. We repeated this random data split and dual GWA analysis process $n_{h}=300$ times to get the standard error of half the distance $[s e(\bar{h})]$ between the 2 peak locations as in Equation [9]: 


$$
s e(\bar{h})=\sqrt{\frac{1}{4 n_{h}} \sum_{l}^{n_{h}} \hat{h}_{l}^{2} .}
$$

Assuming an approximate normal distribution of the peak SNP after $n_{h}$ random splits of the data, we calculated the $99 \%$ CI of the width of the genomic region for the peak SNP marker as in Equation [10]:

$$
99 \% \mathrm{CI}=\hat{x} \pm 2.58 \operatorname{se}(\bar{h})
$$

note that in Equation [10], 2.58 represents the 99.5th percentile of a standard normal distribution.

\section{Proportion of Genetic Variance Explained by the Significant Region}

The proportion of genetic variance explained by each of the 2 regions associated with $\mathrm{AMH}$ was determined by refitting the model in Equation [1], but this time partitioning a into 2 sets of genetic effects for each animal: (1) the contribution of the cumulative effects of the SNP markers falling within the $99 \%$ CI of the peak SNP into $\mathbf{a}_{\text {peak }}=\mathbf{Z}_{\text {peak }} \mathbf{g}_{\text {peak }}$ and that of the remaining markers in $\mathbf{a}_{- \text {peak }}=\mathbf{Z}_{- \text {peak }} \mathbf{g}_{- \text {peak }}$. In other words, we partitioned $\mathbf{a}=\left[\begin{array}{ll}\mathbf{a}_{\text {peak }}^{\prime} & \mathbf{a}_{- \text {peak }}^{\prime}\end{array}\right]^{\prime}$ and $\mathbf{Z}=\left[\begin{array}{ll}\mathbf{Z}_{\text {peak }}^{\prime} & \mathbf{Z}_{- \text {peak }}^{\prime}\end{array}\right]^{\prime}$. Hence, we defined $\operatorname{var}\left(\mathbf{a}_{\text {peak }}\right)=\mathbf{G}_{\text {peak }} \sigma_{a(\text { peak })}^{2}$ and $\operatorname{var}\left(\mathbf{a}_{- \text {peak }}\right)=\mathbf{G}_{- \text {peak }} \sigma_{a(- \text { peak })}^{2}$ with $\mathbf{G}_{\text {peak }}=\mathbf{Z}_{\text {peak }} \mathbf{Z}_{\text {peak }}^{\prime}$ and $\mathbf{G}_{- \text {peak }}=\mathbf{Z}_{- \text {peak }} \mathbf{Z}_{- \text {peak }}^{\prime}$, such that the proportion of genetic variance accounted for by the $99 \%$ CI peak region is estimated as in Equation [11]:

$$
\frac{\hat{\sigma}_{a(\text { peak })}^{2}}{\hat{\sigma}_{a(\text { peak })}^{2}+\hat{\sigma}_{a(- \text { peak })}^{2}},
$$

where $\hat{\sigma}_{a(\text { peak })}^{2}$ is the REML estimate of $\sigma_{a(\text { peak })}^{2}$, and $\hat{\sigma}_{a(-p e a k)}^{2}$ is the REML estimate of $\sigma_{a(-p e a k)}^{2}$. A likelihood ratio test was used to test the importance of the peak region by comparing -2 times the log restricted loglikelihood for the model with 2 genetic variance components $\left[\sigma_{a(p e a k)}^{2}\right.$ and $\left.\sigma_{a(-p e a k)}^{2}\right]$ to that from a null model that only modeled genetic variability outside of the peak $99 \%$ CI region $\left[\sigma_{a(-p e a k)}^{2}\right]$ to a 50:50 mixture of a chi-squared distribution with 0 and 1 df, respectively (Self and Liang, 1987).

Estimation of variance components and GWA analysis was done using the gwaR (https://github.com/steibelj/ gwaR) package in R. All analyses were conducted using $\mathrm{R}$ version 3.2.0 (http://www.R-project.org/).

\section{Identification of Candidate Genes and Enrichment Analysis}

Annotated genes falling within the corresponding 99\% CI for peak SNP associations were retrieved from the Ensembl genome database version 88 of the cow genome (version UMD 3.1; https://www.ensembl.org/ biomart) using the "GenomicRanges" package in $\mathrm{R}$ (Lawrence et al., 2013). This list of candidate genes was submitted to The Database for Annotation, Visualization and Integrated Discovery (DAVID, v6.8 ; Huang et al., 2009) to retrieve the corresponding gene ontology (GO) terms related to biological pathways of all the genes, and to perform gene set enrichment analysis to discover biological pathways that were significantly enriched in the list of candidate genes.

\section{RESULTS AND DISCUSSION}

\section{Descriptive Statistics}

Serum concentrations of AMH in the dairy heifers had a mean of $438.50 \mathrm{pg} / \mathrm{mL}$ and a standard deviation of $604.33 \mathrm{pg} / \mathrm{mL}$. The median AMH concentration was $333.3 \mathrm{pg} / \mathrm{mL}$, with individual AMH values ranging from 2 to $14,350 \mathrm{pg} / \mathrm{mL}$. These concentrations were comparable to those reported in other studies in Holsteins (Guerreiro et al., 2014; Ribeiro et al., 2014), although significant variation exists between breeds of cattle (Batista et al., 2014; Ribeiro et al., 2014) because of differences in reproductive physiology and genetic potential between breeds. The distribution of $\mathrm{AMH}$ concentration and logarithmically transformed AMH concentration (the latter demonstrating a far better approximation to normality) are depicted in Figure 1a and $\mathrm{b}$. Hence, all subsequent analyses are based on the logarithm of AMH.

\section{Heritability Inference and Prediction Accuracies}

The heritability estimate $( \pm \mathrm{SE})$ for $\mathrm{AMH}$ based on pedigree information was $0.43 \pm 0.07$, whereas the estimate of genomic heritability of AMH was $0.36 \pm$ 0.03. The higher pedigree-based heritability may be due to overestimation of additive relationships by the A matrix compared with $\mathbf{G}$ matrix or due to imperfect LD between SNP markers and the QTL controlling the trait. This difference is consistent with those observed in other dairy genetic studies (Veerkamp et al., 2011; Haile-Mariam et al., 2013). Nevertheless, these heritability estimates for AMH are the highest reported for any trait related to reproduction in female cattle (Berry et al., 2014). Gobikrushanth et al. (2018) estimated a similar genomic heritability for AMH $(0.46 \pm 0.31)$ in 
Canadian Holstein cows, albeit with a substantially larger standard error, likely due to their smaller sample size $(\mathrm{n}=198)$. The estimated variance components associated with the day of blood sample collection, genetic and residual variance components, and heritability estimates for both models are provided in Table 1 .

The average reliability of genomic prediction of GEBV for the 2,905 animals was 55.7\% and ranged from
46.5 to $67.2 \%$. Moderate to high reliabilities of GEBV were expected considering the reasonably large genomic heritability estimate for AMH. Reliabilities of genomic prediction are known to increase with the number of animals genotyped, marker density, and the heritability of the trait under selection. The mean reliability for genomic predictions in our study exceeded the expected mean reliability of $36 \%$ for genomic predictions based

a)

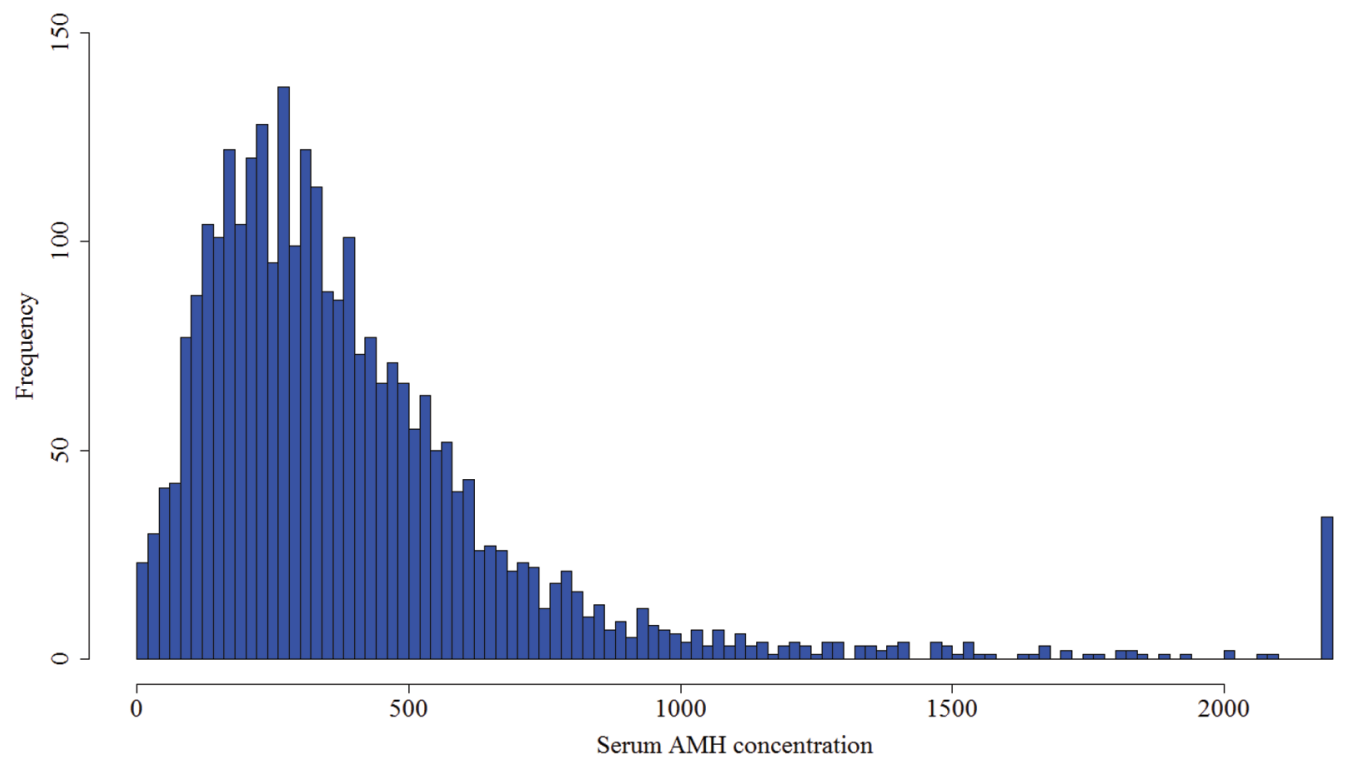

b)

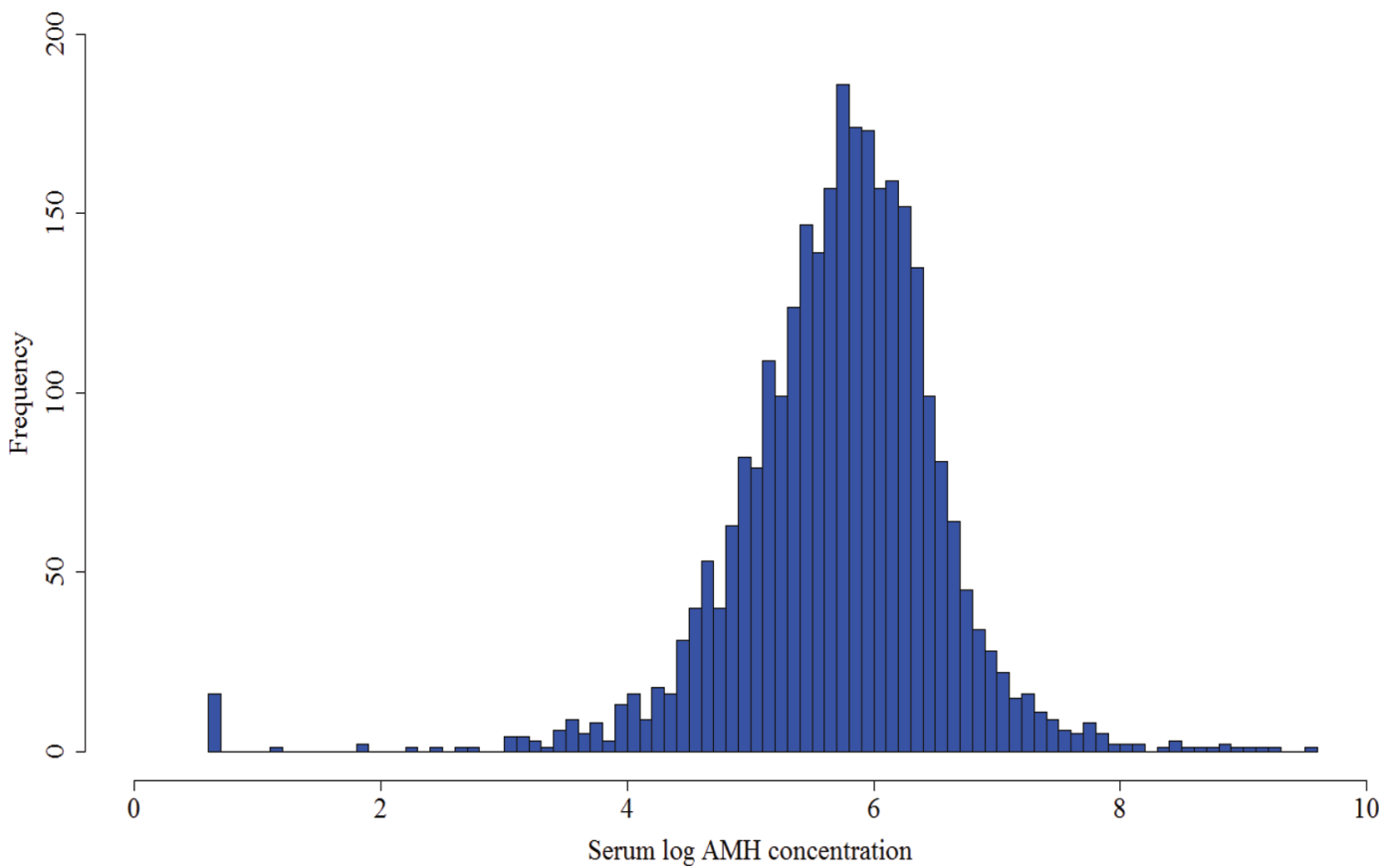

Figure 1. Distribution of (a) serum concentrations and (b) log-transformed serum concentrations of anti-Müllerian hormone (AMH) in Holstein heifers. Color version available online. 


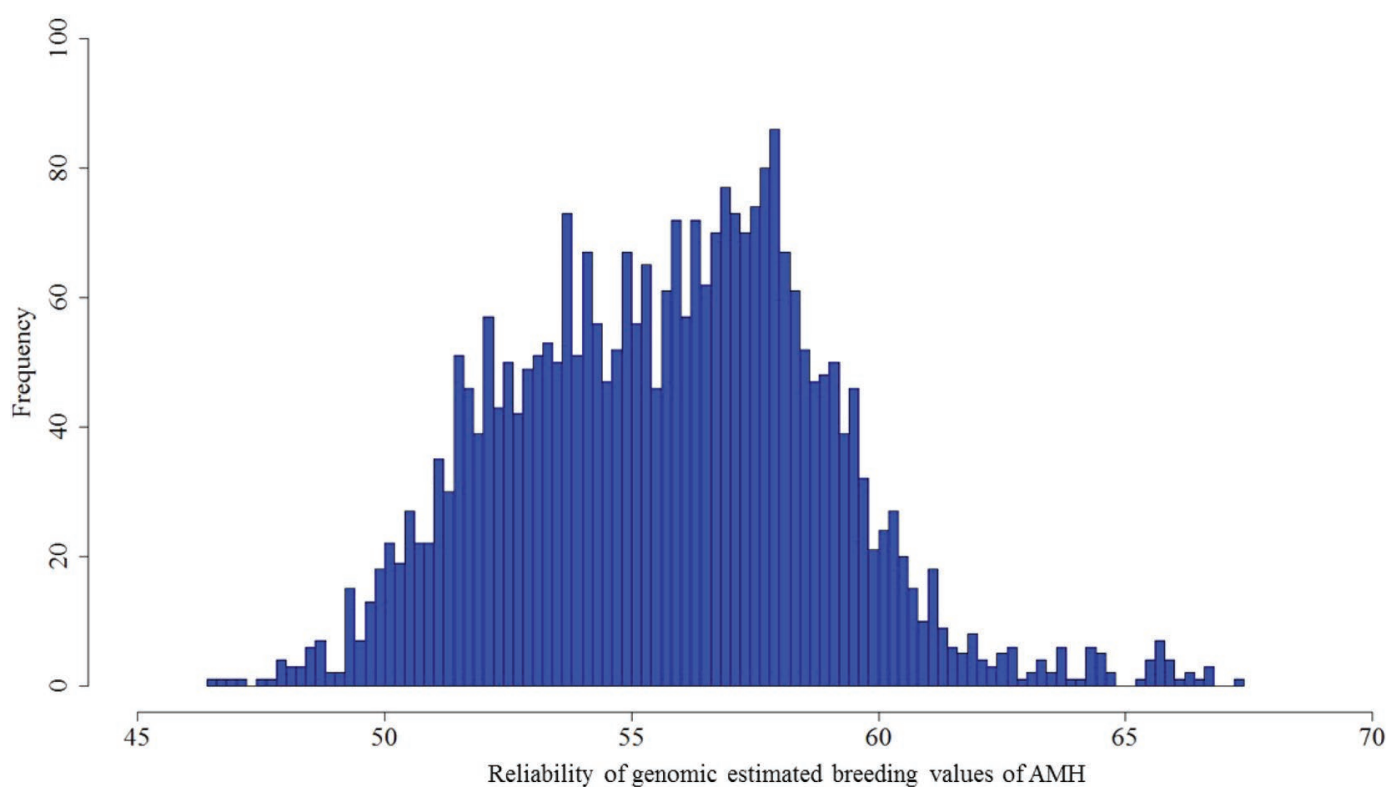

Figure 2. Distribution of reliability of genomic EBV of anti-Müllerian hormone (AMH) using 54,519 SNP markers on 2,905 Holstein heifers. Color version available online.

on a reference population of 3,000 animals and a trait heritability of 0.35 , as expected by Hayes et al. (2009). The distribution of prediction accuracies for the 2,905 animals is provided in Figure 2. Hence, genetic selection on $\mathrm{AMH}$ could improve reproductive potential in cattle, provided that a positive genetic correlation exists between $\mathrm{AMH}$ and economically relevant reproduction traits.

It has previously been established that $\mathrm{AMH}$ has a moderate phenotypic correlation with the average and maximal number of embryos collected per cow $(\mathrm{r}=$ $0.49, P<0.001$; and $\mathrm{r}=0.58, P<0.0001$, respectively) (Monniaux et al., 2010). Jaton et al. (2016) demonstrated that genetic correlations between the number of collectible and viable embryos and milk production traits were low, ranging between -0.12 and -0.29 , and concluded that the genetic selection of cattle that produce a large number of embryos without compromising milk production is plausible. Given that our estimated heritability of AMH is more than twice that (0.14) estimated for the number of embryos by Jaton et al. (2016), indirect selection on serum AMH in young animals could allow earlier and more accurate selection for the number of embryos in both cows and bulls, provided that the genetic correlation between the 2 traits is large (Woolliams and Smith, 1988). Although superovulatory traits are not yet included in the dairy breeding goals, estimating breeding values for AMH would be useful for breeders who are interested in maximizing their efficiency of embryo production by selecting animals as donors based on their genetic potential for superovulation.

\section{GWA Study}

Significant associations between AMH and SNP markers were found in 2 distinct regions of the genome, one within each of chromosomes 11 and 20 . The most significant association was with SNP marker Hapmap41435-BTA-115556 on BTA11 at position $95,026,013 \mathrm{bp}$, whereas the sole significant association on BTA20 was with SNP marker ARS-BFGL-NGS-110286 at position 25,689,084 bp. Genome-wide association inferences are best illustrated by a Manhattan plot [plot of $-\log _{10}(P$-values $)$ versus genomic location] overlain with a statistical significance threshold reference line,

Table 1. Estimates $( \pm \mathrm{SE})$ of variance components and heritability of anti-Müllerian hormone (AMH) from models based on pedigree information and genomic information

\begin{tabular}{lcccc}
\hline Model & $\begin{array}{c}\text { Genetic } \\
\text { variance }\end{array}$ & $\begin{array}{c}\text { Sampling day } \\
\text { variance }\end{array}$ & $\begin{array}{c}\text { Residual } \\
\text { variance }\end{array}$ & Heritability \\
\hline Pedigree-based & $0.34 \pm 0.05$ & $0.02 \pm 0.01$ & $0.42 \pm 0.04$ & $0.43 \pm 0.07$ \\
SNP marker-based & $0.28 \pm 0.01$ & $0.02 \pm 0.01$ & $0.48 \pm 0.02$ & $0.36 \pm 0.03$ \\
\hline
\end{tabular}




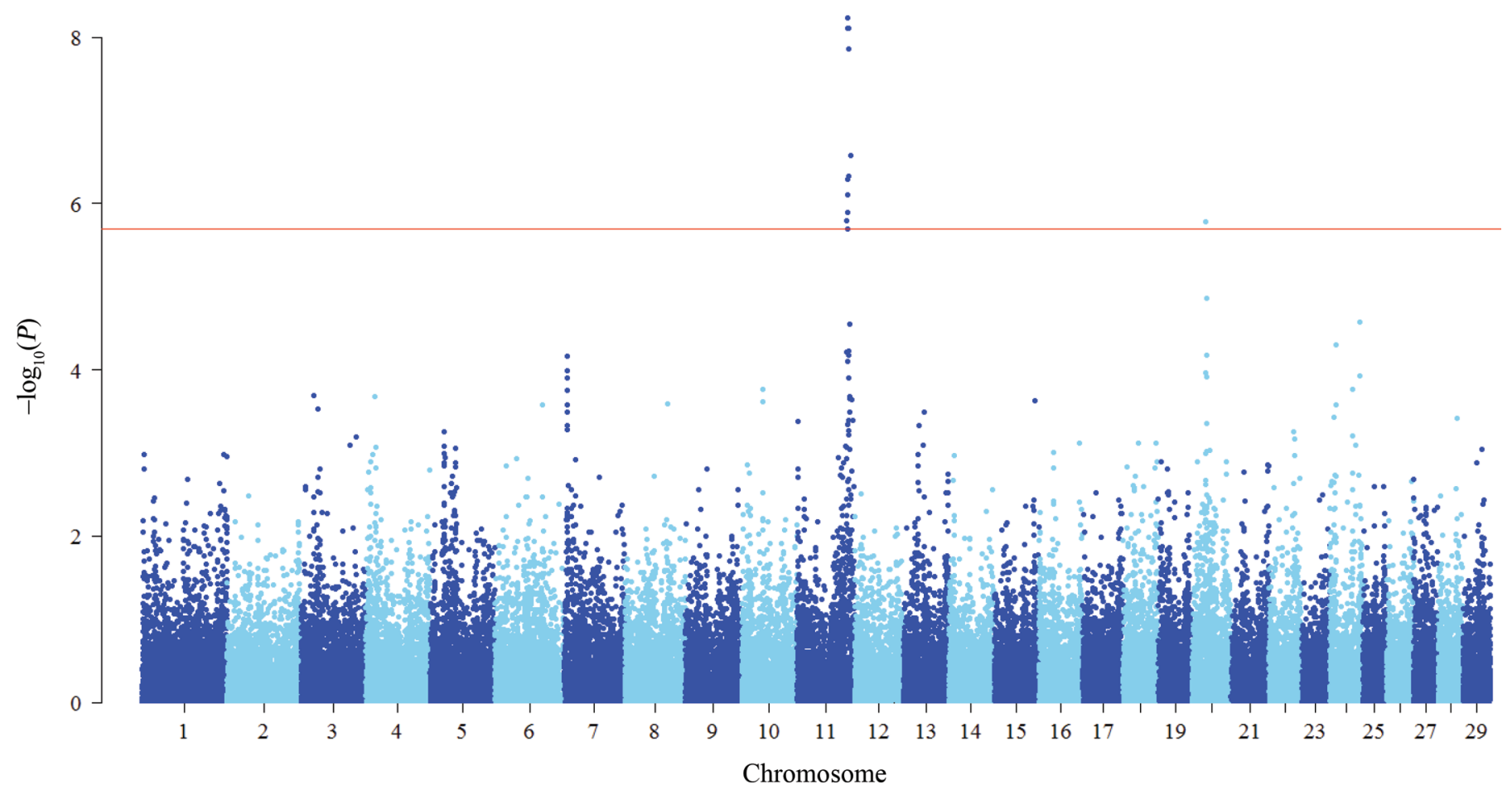

Figure 3. Manhattan plot of $-\log _{10} P$-values versus genomic location for logarithm of serum concentrations of anti-Müllerian hormone $(\mathrm{AMH})$ in dairy Holstein heifers. Horizontal reference line corresponds to false discovery rate of $5 \%$ superimposed. Color version available online.

as provided in Figure 3. This plot demonstrates significant associations between AMH and 11 SNP markers within 1 genomic region on BTA11 and 1 SNP marker on BTA20 based on an FDR of $5 \%$. The names of all significant SNP markers and their corresponding $P$ values are provided in Table 2 .

\section{Inferring Number of QTL}

To assess whether evidence of more than one QTL might exist within the particular genomic region of 11 significant SNP markers on BTA11, the most sig- nificant SNP marker, Hapmap41435-BTA-115556, was included as a fixed effect in the model. Upon doing so, none of the remaining SNP markers on BTA11 reached the level of statistical significance (5\% FDR). This suggests that all significant SNP associations on BTA11 were not due to the presence of multiple QTL; however, we also recognize that this procedure may not be very sensitive to detecting multiple QTL within the same region for markers in high LD with each other. Because there was only one significant marker association on BTA20, this process was not considered within that region.

Table 2. Significant marker associations from genome-wide association analysis of logarithm of anti-Müllerian hormone (AMH) in dairy Holstein heifers (SNP identifiers can be found at http://bioinformatics.tecnoparco.org/SNPchimp/)

\begin{tabular}{|c|c|c|c|c|c|}
\hline SNP ID & BTA & Position (bp) & $P$-value & $q$-value & $\begin{array}{l}\text { Minor allele } \\
\text { frequency }\end{array}$ \\
\hline BTA-17666-no-rs & 11 & $92,059,274$ & $1.59 \times 10^{-6}$ & 0.007 & 0.18 \\
\hline ARS-BFGL-NGS-118517 & 11 & $93,546,324$ & $1.29 \times 10^{-6}$ & 0.007 & 0.47 \\
\hline BTA-115525-no-rs & 11 & $94,101,466$ & $7.77 \times 10^{-9}$ & 0.0001 & 0.20 \\
\hline BovineHD1100027436 & 11 & $94,202,912$ & $2.00 \times 10^{-6}$ & 0.008 & 0.22 \\
\hline Hapmap46766-BTA-115526 & 11 & $94,446,742$ & $7.92 \times 10^{-7}$ & 0.005 & 0.22 \\
\hline Hapmap47514-BTA-115564 & 11 & $96,074,475$ & $7.87 \times 10^{-9}$ & 0.00013 & 0.16 \\
\hline ARS-BFGL-NGS-114094 & 11 & $99,413,363$ & $2.63 \times 10^{-7}$ & 0.00279 & 0.10 \\
\hline ARS-BFGL-NGS-110286 & 20 & $25,689,084$ & $1.64 \times 10^{-6}$ & 0.00794 & 0.46 \\
\hline
\end{tabular}




\section{Confidence Interval of the Peak SNP Association on Chromosomes 11 and 20}

Based on the procedures adapted from Casiró et al. (2017), we determined that the 99\% CI of the peak SNP on BTA11 ranged from $92,879,023$ to $97,160,473 \mathrm{bp}$, a span of roughly $4.28 \mathrm{Mbp}$. Our SNP panel contained 68 SNP markers from that region which accounted for $7.9 \%$ of the total genetic variance. The genetic variance for this region was determined to be significant $(P=$ $1.7 \times 10^{-7}$ ) based on a likelihood ratio test. Similarly, the $99 \%$ CI of the peak significant marker on BTA20 (ARS-BFGL-NGS-110286) ranged from 25,002,762 to $26,362,752 \mathrm{bp}$, a span of roughly $1.35 \mathrm{Mbp}$. This chromosomal region contained 25 SNP markers and accounted for $5.25 \%$ of the genetic variance, which was also deemed to be significant $(P=0.007)$ based on a likelihood ratio test. Therefore, the proportion of total genetic variance jointly explained by both regions in BTA11 and BTA20 was $13.25 \%$.

Since the original submission of this paper, a concurrent GWA study (Gobikrushanth et al., 2018) has identified 640 significant SNP marker associations spread over 12 chromosomes with serum AMH drawn from 589 mature Canadian Holstein cows. In that study, 513 of the 640 associations substantially overlapped with our own region of inferred associations on BTA11, although we did infer a narrower region using a cross validation approach, as explained above, in part due to our substantially larger sample sizes. Their greater number of declared associations could be partly attributed to primarily imputed associations as the cows in the Gobikrushanth et al. (2018) study were genotyped with a lower density panel $(\sim 26 \mathrm{~K})$ imputed in 2 steps to the Illumina Bovine 50K panel (Illumina Inc., San Diego, $\mathrm{CA}$ ) and then to the Bovine HD $777 \mathrm{~K}$ panel (Illumina Inc.) using an Irish Holstein-Friesian reference population. Their GWA analysis was conducted such that for the SNP marker association being tested, none of the effects of the other markers on the same chromosome were simultaneously fitted; conversely, our SNP marker association tests were adjusted for all other SNP markers, including those on the same chromosome as the marker of interest. Furthermore, their $P$-value threshold for declaring significant associations was less stringent (about one order of magnitude) than our corresponding threshold even though their number of marker tests was far greater.

In humans, Perry et al. (2016) determined that 3 SNP variants close to the AMH gene locus on chromosome 19 were associated with $\log$ serum AMH. Their GWA analyses also inferred a sex interaction effect because no SNP markers were deemed associated with AMH in females. As our study consisted of heifers only, we could not assess whether such an interaction existed for serum AMH levels in cattle. Considering AMH as an indicator of reproduction traits, we also reviewed GWA studies for reproduction traits in Holstein to find any evidence of overlap of associations with our results. A GWA study on superovulatory traits in dairy cattle (Jaton et al., 2018) concluded that 26 of 36 significant marker associations with total number of embryos and all 14 significant markers associated with the number of viable embryos were located between 92,918,581 and $97,926,706 \mathrm{bp}$ on BTA11. That study, in conjunction with ours, further strengthens the hypothesis that AMH has a common QTL with superovulatory response traits in cattle, with both traits being regulated by common genes, given that strong phenotypic associations between the 2 traits have already been well established.

\section{Candidate Genes and Functional Enrichment}

The $99 \%$ CI of the most significant association on BTA11 (92,879,023 to $97,160,473 \mathrm{bp})$ contained 81 potential candidate genes, whereas the corresponding region on BTA20 (25,002,762 to $26,362,752 \mathrm{bp}$ ) contained 9 potential candidate genes based on the Ensembl genome database v. 88 of the cow genome. Therefore, 90 genes were submitted to DAVID to retrieve functional GO information; 69 genes were successfully mapped to the DAVID Bos taurus GO database (Supplemental Tables S1 and S2; https://doi.org/10.3168/jds.2018 -14798). Gene set enrichment analysis using DAVID resulted in identification of 2 GO terms (biological pathways) significantly enriched $\left(P\right.$-values $<10^{-13}$ ) in the list of candidate genes compared with the background genes of Bos taurus (Table 3). These terms were the "G-protein coupled receptor signaling" (GO:0007186) and "detection of chemical stimulus involved in sensory perception" (GO:0050907) pathways. The former pathway begins with receptor-ligand interaction and ends with the regulation of a downstream cellular process (e.g., transcription). The latter is involved in a series of events in which a chemical stimulus is received and converted into a molecular signal as part of sensory perception. Although it is unclear at this point how these pathways specifically affect serum AMH concentration, it is apparent that the genes involved in cell-to-cell signaling mechanisms are key regulators of AMH. Some of the other interesting GO terms associated with candidate genes include "male gonad development" (GO:0008584), "multicellular organism aging" (GO:0010259), "steroid hormone mediated signaling pathway" (GO:0043401), "positive regulation of male gonad development" (GO:2000020), "negative regulation of female gonad development" (GO:2000195), and 
Table 3. Biological pathways significantly associated with log serum anti-Müllerian hormone (AMH) concentrations in heifers

\begin{tabular}{lcrc}
\hline Gene ontology terms & $\begin{array}{c}\text { No. of genes } \\
\text { matched/total }\end{array}$ & $\begin{array}{c}\text { Fold } \\
\text { enrichment }\end{array}$ & $\begin{array}{c}\text { False } \\
P \text {-value }\end{array}$ \\
\hline GO:0007186 G-protein coupled receptor signaling pathway & $24 / 69$ & 7.78 & $3.0 \times 10^{-15}$ \\
GO:0050907 Detection of chemical stimulus involved & $13 / 69$ & 21.02 & $6.3 \times 10^{-13}$ \\
in sensory perception & & $7.5 \times 10^{-12}$ \\
\hline
\end{tabular}

"gamete generation" (GO:0007276), among many others. One potential limitation of this GO analysis is that all of these candidate genes derive from only 2 narrowly defined regions of the genome (i.e., a 4.28-Mbp region on BTA11 and a 1.35-Mbp region on BTA20). Hence, any such inferred associations may be biased if nonrandom associations exist between genomic locations and functional processes of the resident genes. All candidate genes and their corresponding GO terms retrieved from DAVID are listed in Supplemental Tables S1 (BTA11) and S2 (BTA20; https://doi.org/10.3168/jds.2018 -14798).

We propose that all the genes lying within the $99 \%$ CI for the peak SNP are potential candidates for understanding molecular mechanisms for the regulation of AMH. A literature search of candidate genes revealed that several of these candidates (DENND1A, NR5A1, NR6A1, PTGS1, and NDUFA8 on BTA11; and FST on BTA20) have a plausibly important role in AMH regulation in cattle based on previous studies as subsequently outlined. The most significant association (Hapmap41435-BTA-115556) with AMH in our study was located within the intronic region of the DENND1A gene. This gene has a role in membrane trafficking and receptor turnover. Welt et al. (2012) determined that the marker rs10986105, also located within DENND1A, had the most significant association with polycystic ovarian syndrome (PCOS) for European and Chinese human females. It is well known that women suffering from PCOS are subfertile (Franks, 1995), have a large number of ovarian follicles (Hughesdon, 1982) and abnormally high serum AMH concentrations (Pigny et al., 2003), and exhibit high RNA expression of the DENND1A gene in thecal cells and enhanced circulating concentrations of androgens and progesterone (McAllister et al., 2015). These phenotypic characteristics in women are similar to those in cattle having a high antral follicle count, which is also associated with reduced reproductive performance and shortened herd longevity (Jimenez-Krassel et al., 2017) as well as high circulating concentrations of testosterone (Mossa et al., 2010) and progesterone (Ireland et al., 2009), and high circulating AMH concentrations (Ireland et al., 2008). In addition, $D E N N D 1 A$ was identified as a candidate gene on BTA11 in a recent GWA study involving superovulatory responses (total number of embryos and the number of viable embryos) in Canadian Holstein dairy cows (Jaton et al., 2018). This linkage with our study is particularly significant because, again, AMH concentration is known to be positively correlated with the response to superovulation in dairy cows (Monniaux et al., 2010).

The prostaglandin-endoperoxide synthase 1 (PTGS1) gene (commonly known as COX-1) is responsible for the conversion of arachidonic acid into $\mathrm{PGH}_{2}$, a precursor of all forms of prostaglandins such as $\mathrm{PGE}_{2}$ and $\mathrm{PGF}_{2 \alpha}$ (Arosh et al., 2002). Prostaglandins are well known to play an important role in ovulation and fertilization (Armstrong, 1981) by either contracting or relaxing the muscles of the oviduct, leading to rapid transport of gametes and zygote (Wijayagunawardane et al., 2001). Although PTGS1 is constantly expressed in many tissues and cell types (Asselin et al., 1997), the concentration of PTGS1 mRNA consistently increases in the oviduct from uterine pole toward the ovarian pole, independent of the stage of estrous cycle (Gauvreau et al., 2010), suggesting its significance in the oviduct, which serves as the site of fertilization and transports the gametes and zygote to the uterus. Moreover, PTGS1 has been associated with the number of collectible embryos and number of viable embryos in Canadian Holsteins (Jaton et al., 2018). As AMH has been identified as an important marker of superovulatory response (Monniaux et al., 2010; Souza et al., 2015), these findings suggest an important role for PTGS1 in the regulation of AMH and superovulation.

Our study also identified 2 microRNAs, miR-181a and miR181b, that have been shown to be induced by AMH in a mouse model (Hayes et al., 2016). In vivo treatment of $\mathrm{AMH}$ induces expression of miR-181a in mouse ovary that targets activin receptor (ACVR2A) leading to disruption of activin effects on follicular growth. Furthermore, AMH also induces miR-181b expression that targets adenylate cyclase 9 (ADCY9), decreasing cyclic AMP levels and resulting in suppression of FSH signaling. Our results, coupled with the fact that similar results were also found in human granulosa-like tumor cell line (KGN cells; Hayes et al., 2016), suggest that molecular mechanisms of AMH are conserved across species.

The NR5A1 gene encodes steroidogenic factor 1 (SF1 ), which is known to bind to 2 binding sites within 
the promoter region of AMH gene (Giuili et al., 1997; Watanabe et al., 2000) and regulates AMH expression (Jin et al., 2016). In addition, the SF-1 binding site to the AMH promoter is known to be essential for sexand cell-specific AMH promoter activity (Giuili et al., 1997) and transcription of key genes involved in sexual development and reproduction. Similarly, NR6A1 (also known as germ cell nuclear factor, $G C N F$ ), which encodes an oocyte-specific transcription repressor (Cooney et al., 1998), belongs to the same family as NR5A1 and is known to play an important role in embryo development and folliculogenesis (Pangas and Rajkovic, 2006).

The NDUFA8 gene encodes a subunit of enzyme $\mathrm{NADH}$ dehydrogenase (ubiquinone), which is located in the mitochondrial inner membrane and transfers electrons with high redox potential from NADH to ubiquinone, thus playing an important role in energy metabolism (Held et al., 2012). Gene expression of NDUFA8 is downregulated in competent bovine embryos (O'Shea et al., 2012). However, this gene is highly expressed in human heart, skeletal muscle, and fetal heart (Triepels et al., 1998). Moreover, a GWA study in cattle with brisket disease revealed NADH dehydrogenase as a candidate gene involved in hypertension (Newman et al., 2011). Recently, AMH concentration has been found to be negatively correlated with ultrasonographic diameter of the aorta, whereas high AMH levels have been linked to the absence of cardiovascular disease in men (Dennis et al., 2013). In addition, female offspring of beef cows fed a mild nutrient-restricted diet during the first trimester of pregnancy not only had significantly larger aortic diameters and higher blood pressure but also lower circulating AMH concentrations compared with controls (Mossa et al., 2013). Taken together, these studies in humans and cattle potentially demonstrate a previously unstudied link between AMH concentrations and cardiovascular health.

The FST gene encodes the protein follistatin, which binds to members of the TGF- $\beta$ superfamily, particularly activin. Follistatin was first discovered in follicular fluid and known to bind to activins and inhibit activininduced secretion of FSH from pituitary gland (Ying, 1988). Follistatin and activin interaction is widely known as the autocrine/paracrine regulator of various physiological processes in reproduction, including folliculogenesis and maturation of oocytes (Muttukrishna et al., 2004). Furthermore, increased abundance of FST mRNA transcript is positively associated with competence of fertilized bovine oocytes to develop into embryos (Patel et al., 2007; Lee et al., 2009). Follistatin enhances AMH signaling in luciferase reporter assays (Kawagishi et al., 2017), implying that it may have a role in regulation of $\mathrm{AMH}$ bioactivity.

\section{Future Research Questions}

A limitation of our study is that all the data were collected from a single farm and consisted of females only. It would be informative to conduct a GWA with a larger data set consisting of both sexes to determine whether there is a sex interaction effect, as found in humans, or whether the genetic correlation in AMH between bulls and cows is different from unity. The existence of such an interaction could affect genomic selection programs for AMH. Second, widespread application of AMH as a diagnostic tool to select superior dairy animals for reproductive traits requires further research involving animals in different stages of productive life and under different management conditions. Future studies should be considered to infer the phenotypic and genetic correlations of AMH with economically relevant traits in the dairy industry, especially superovulatory traits, as anticipated by our results in conjunction with those of Jaton et al. (2018). A multiple trait analysis could assess whether AMH could be used for indirect genetic improvement of reproduction in cattle without any deleterious effects on production traits, for example.

Candidate genes identified in this study also require further study. Some of these genes have already been studied extensively in the past. For example, NR5A1 knockout mice showed complete adrenal and gonadal agenesis (Luo et al., 1994), and mutations in this gene caused ovarian insufficiency (Lourenço et al., 2009). However, validation of other genes should be tested by a series of experiments. First, fine sequencing should be done in the proposed genomic regions to detect the causative QTL. These studies could be followed by differential gene expression studies and knockout experiments to confirm the role of candidate genes in the regulation of AMH. Moreover, a gene network analysis using publicly available scientific data sets on genes and pathways can reveal important protein-protein and gene-gene interactions among the candidate genes of AMH. These studies can provide important information to design gene knockout experiments to explore drug targets for treatment of subjects with unusually high or low AMH concentration.

\section{CONCLUSIONS}

Serum concentration of AMH is a complex trait (controlled by several QTL) like most other quantitative traits. We estimated a heritability $(0.36 \pm 0.03)$ for $\mathrm{AMH}$ that was large relative to economically important reproductive traits. The moderate to high heritability of $\mathrm{AMH}$ along with the known positive association of $\mathrm{AMH}$ concentration with numerous indirect and direct 
measures of fertility in cattle indicate that $\mathrm{AMH}$ might be useful to indirectly improve predictions of genetic merit of some reproductive traits. Our GWA study, in conjunction with another recent GWA study on superovulatory responses in dairy cattle, further indicates considerable overlap between the genes that influence serum AMH and those that affect superovulatory traits in cattle. Future studies are needed to further establish the genetic correlation of $\mathrm{AMH}$ with superovulation and other economically important traits in dairy cattle.

\section{ACKNOWLEDGMENTS}

The study was supported by the Agriculture and Food Research Initiative National Institute of Food and Agriculture (Washington, DC; grant no. 2013-6701520962) and the Fulbright Masters and PhD Program, Pakistan, funded by the United States Agency for International Development (USAID, Washington, DC). The authors declare no conflict of interest.

\section{REFERENCES}

Allard, S., P. Adin, L. Gouedard, N. di Clemente, N. Josso, M. C. Orgebin-Crist, J. Y. Picard, and F. Xavier. 2000. Molecular mechanisms of hormone-mediated Müllerian duct regression: Involvement of $\beta$-catenin. Development 127:3349-3360.

Armstrong, D. T. 1981. Prostaglandins and follicular functions. J. Reprod. Fertil. 62:283-291.

Arosh, J. A., J. Parent, P. Chapdelaine, J. Sirois, and M. A. Fortier. 2002. Expression of cyclooxygenases 1 and 2 and prostaglandin E synthase in bovine endometrial tissue during the estrous cycle. Biol. Reprod. 67:161-169. https://doi.org/10.1095/biolreprod67.1 .161.

Asselin, E., P. Droplet, and M. A. Fortier. 1997. Cellular mechanisms involved during oxytocin-induced prostaglandin F2 production in endometrial epithelial cells in vitro: Role of cyclooxygenase-2. Endocrinology 138:4798-4805. https://doi.org/10.1210/endo.138.11 .5527 .

Baarends, W. M., M. J. van Helmond, M. Post, P. J. van der Schoot, J. W. Hoogerbrugge, J. P. de Winter, J. T. Uilenbroek, B. Karels, L. G. Wilming, and J. H. Meijers. 1994. A novel member of the transmembrane serine/threonine kinase receptor family is specifically expressed in the gonads and in mesenchymal cells adjacent to the mullerian duct. Development 120:189-197.

Batista, E. O. S., G. G. Macedo, R. V. Sala, M. D. D. V. Ortolan, M. F. Sá Filho, T. A. Del Valle, E. F. Jesus, R. N. V. R. Lopes, F. P. Rennó, and P. S. Baruselli. 2014. Plasma antimullerian hormone as a predictor of ovarian antral follicular population in Bos indicus (Nelore) and Bos taurus (Holstein) heifers. Reprod. Domest. Anim. 49:448-452. https://doi.org/10.1111/rda.12304.

Berry, D. P., E. Wall, and J. E. Pryce. 2014. Genetics and genomics of reproductive performance in dairy and beef cattle. Animal 8(Suppl 1):105-121. https://doi.org/10.1017/S1751731114000743.

Casiró, S., D. Velez-Irizarry, C. W. Ernst, N. E. Raney, R. O. Bates, M. G. Charles, and J. P. Steibel. 2017. Genome-wide association study in an F2 Duroc x Pietrain resource population for economically important meat quality and carcass traits. J. Anim. Sci. https://doi.org/10.2527/jas.2016.1003.

Cooney, A. J., G. C. Hummelke, T. Herman, F. Chen, and K. J. Jackson. 1998. Germ cell nuclear factor is a response element-specific repressor of transcription. Biochem. Biophys. Res. Commun. 245:94-100. https://doi.org/10.1006/bbrc.1998.8391.
Dennis, N. A., G. T. Jones, Y. H. Chong, A. M. van Rij, and I. S. McLennan. 2013. Serum anti-Mullerian hormone (AMH) levels correlate with infrarenal aortic diameter in healthy older men: Is AMH acardiovascular hormone? J. Endocrinol. 219:13-20. https:// doi.org/10.1530/JOE-13-0125.

Durlinger, A. L. L., M. J. G. Gruijters, P. Kramer, B. Karels, T. R. Kumar, M. M. Matzuk, U. M. Rose, F. H. De Jong, J. T. J. Uilenbroek, J. A. Grootegoed, and A. P. N. Themmen. 2001. AMH attenuates the effects of FSH on follicle development in the mouse ovary. Endocrinology 142:4891-4899. https://doi.org/10.1210/ endo.142.11.8486.

Durlinger, A. L., M. J. Gruijters, P. Kramer, B. Karels, H. A. Ingraham, M. W. Nachtigal, J. T. Uilenbroek, J. A. Grootegoed, and A. P. Themmen. 2002. Anti-Mullerian hormone inhibits initiation of primordial follicle growth in the mouse ovary. Endocrinology 143:1076-1084.

Durlinger, A. L., P. Kramer, B. Karels, F. H. de Jong, J. T. Uilenbroek, J. A. Grootegoed, and A. P. Themmen. 1999. Control of primordial follicle recruitment by anti-Mullerian hormone in the mouse ovary. Endocrinology 140:5789-5796. https://doi.org/10 .1210 /endo.140.12.7204.

Franks, S. 1995. Polycystic ovarian syndrome. N. Engl. J. Med. 333:853-861.

García-Ruiz, A., J. B. Cole, P. M. VanRaden, G. R. Wiggans, F. J. Ruiz-López, and C. P. Van Tassell. 2016. Changes in genetic selection differentials and generation intervals in US Holstein dairy cattle as a result of genomic selection. Proc. Natl. Acad. Sci. USA 113:E3995-E4004. https://doi.org/10.1073/pnas.1519061113.

Gauvreau, D., V. Moisan, M. Roy, M. A. Fortier, and J. F. Bilodeau. 2010. Expression of prostaglandin $\mathrm{E}$ synthases in the bovine oviduct. Theriogenology 73:103-111. https://doi.org/10.1016/j .theriogenology.2009.08.006.

Giuili, G., W. H. Shen, and H. A. Ingraham. 1997. The nuclear receptor SF-1 mediates sexually dimorphic expression of Mullerian Inhibiting Substance, in vivo. Development 124:1799-1807.

Gobikrushanth, M., D. C. Purfield, M. G. Colazo, S. T. Butler, Z Wang, and D. J. Ambrose. 2018. The relationship between serum anti-Mullerian hormone (AMH) concentrations and fertility, and genome wide associations for AMH in Holstein dairy cows. J. Dairy Sci. 101:7563-7574. https://doi.org/10.3168/jds.2017-13940.

Gualdrón Duarte, J. L., R. J. C. Cantet, R. O. Bates, C. W. Ernst, N. E. Raney, and J. P. Steibel. 2014. Rapid screening for phenotypegenotype associations by linear transformations of genomic evaluations. BMC Bioinformatics 15:246. https://doi.org/10.1186/1471 $-2105-15-246$.

Guerreiro, B. M., E. O. S. Batista, L. M. Vieira, M. F. Sá Filho, C. A. Rodrigues, A. C. Netto, C. R. A. Silveira, B. M. Bayeux, E. A R. Dias, F. M. Monteiro, M. Accorsi, R. N. V. R. Lopes, and P. S. Baruselli. 2014. Plasma anti-Mullerian hormone: An endocrine marker for in vitro embryo production from Bos taurus and Bos indicus donors. Domest. Anim. Endocrinol. 49:96-104. https://doi .org/10.1016/j.domaniend.2014.07.002.

Haile-Mariam, M., G. J. Nieuwhof, K. T. Beard, K. V. Konstatinov, and B. J. Hayes. 2013. Comparison of heritabilities of dairy traits in Australian Holstein-Friesian cattle from genomic and pedigree data and implications for genomic evaluations. J. Anim. Breed. Genet. 130:20-31. https://doi.org/10.1111/j.1439-0388.2013.01001 $\mathrm{x}$.

Hayes, B. 2013. Overview of Statistical Methods for Genome-Wide Association Studies (GWAS). Springer Science+Business Media, Berlin, Germany.

Hayes, B. J., P. J. Bowman, A. J. Chamberlain, and M. E. Goddard. 2009. Invited review: Genomic selection in dairy cattle: Progress and challenges. J. Dairy Sci. 92:433-443. https://doi.org/10.3168/ jds.2008-1646.

Hayes, E., V. Kushnir, X. Ma, A. Biswas, H. Prizant, N. Gleicher, and A. Sen. 2016. Intra-cellular mechanism of anti-Müllerian hormone $(\mathrm{AMH})$ in regulation of follicular development. Mol. Cell. Endocrinol. 433:56-65. https://doi.org/10.1016/j.mce.2016.05.019.

Held, E., D. Salilew-Wondim, M. Linke, U. Zechner, F. Rings, D. Tesfaye, K. Schellander, and M. Hoelker. 2012. Transcriptome finger- 
print of bovine 2-cell stage blastomeres is directly correlated with the individual developmental competence of the corresponding sister blastomere. Biol. Reprod. 87:154. https://doi.org/10.1095/ biolreprod.112.102921.

Huang, W., B. T. Sherman, and R. A. Lempicki. 2009. Bioinformatics enrichment tools: Paths toward the comprehensive functional analysis of large gene lists. Nucleic Acids Res. 37:1-13. https://doi .org/10.1093/nar/gkn923.

Hughesdon, P. E. 1982. Morphology and morphogenesis of the SteinLeventhal ovary and of so-called "hyperthecosis". Obstet. Gynecol. Surv. 37:59-77.

Ireland, J. J., G. W. Smith, D. Scheetz, F. Jimenez-Krassel, J. K. Folger, J. L. H. Ireland, F. Mossa, P. Lonergan, and A. C. O. Evans. 2011. Does size matter in females? An overview of the impact of the high variation in the ovarian reserve on ovarian function and fertility, utility of anti-Müllerian hormone as a diagnostic marker for fertility and causes of variation in the ovarian reserve in cattle. Reprod. Fertil. Dev. 23:1-14. https://doi.org/10.1071/RD10226.

Ireland, J. J., F. Ward, J. L. H. Ireland, G. W. Smith, P. Lonergan, and A. C. O. Evans. 2007. Follicle numbers are highly repeatable within individual animals but are inversely correlated with FSH concentrations and the proportion of good-quality embryos after ovarian stimulation in cattle. Hum. Reprod. 22:1687-1695.

Ireland, J. J., A. E. Zielak-Steciwko, F. Jimenez-Krassel, J. Folger, A. Bettegowda, D. Scheetz, S. Walsh, F. Mossa, P. G. Knight, G. W. Smith, P. Lonergan, and A. C. O. Evans. 2009. Variation in the ovarian reserve is linked to alterations in intrafollicular estradiol production and ovarian biomarkers of follicular differentiation and oocyte quality in cattle. Biol. Reprod. 80:954-964. https://doi .org/10.1095/biolreprod.108.073791.

Ireland, J. L., D. Scheetz, F. Jimenez-Krassel, A. P. Themmen, F. Ward, P. Lonergan, G. W. Smith, G. I. Perez, A. C. Evans, and J. J. Ireland. 2008. Antral follicle count reliably predicts number of morphologically healthy oocytes and follicles in ovaries of young adult cattle. Biol. Reprod. 79:1219-1225. https://doi.org/10.1095/ biolreprod.108.071670.

Jaton, C., A. Koeck, M. Sargolzaei, F. Malchiodi, C. A. Price, F. S. Schenkel, and F. Miglior. 2016. Genetic analysis of superovulatory response of Holstein cows in Canada. J. Dairy Sci. 99:3612-3623. https://doi.org/10.3168/jds.2015-10349.

Jaton, C., F. S. Schenkel, M. Sargolzaei, A. Cánovas, F. Malchiodi, C. A. Price, C. Baes, and F. Miglior. 2018. Genome-wide association study and in silico functional analysis of the number of embryos produced by Holstein donors. J. Dairy Sci. 101:7248-7257. https://doi.org/10.3168/jds.2017-13848.

Jimenez-Krassel, F., D. M. Scheetz, L. M. Neuder, J. L. H. Ireland, J. R. Pursley, G. W. Smith, R. J. Tempelman, T. Ferris, W. E. Roudebush, F. Mossa, P. Lonergan, A. C. O. Evans, and J. J. Ireland. 2015. Concentration of anti-Müllerian hormone in dairy heifers is positively associated with productive herd life. J. Dairy Sci. 98:3036-3045. https://doi.org/10.3168/jds.2014-8130.

Jimenez-Krassel, F., D. M. Scheetz, L. M. Neuder, J. R. Pursley, and J. J. Ireland. 2017. A single ultrasound determination of $\geq 25$ follicles $\geq 3 \mathrm{~mm}$ in diameter in dairy heifers is predictive of a reduced productive herd life. J. Dairy Sci. 100:5019-5027. https://doi.org/ 10.3168/jds.2016-12277.

Jin, H., M. Won, S. E. Park, S. Lee, M. Park, and J. Bae. 2016. FOXL2 is an essential activator of SF-1- induced transcriptional regulation of anti-Müllerian hormone in human granulosa cells. PLoS One 11:e0159112. https://doi.org/10.1371/journal.pone.0159112.

Kawagishi, Y., M. W. Pankhurst, Y. Nakatani, and I. S. McLennan 2017. Anti-Müllerian hormone signaling is influenced by Follistatin 288 , but not 14 other transforming growth factor beta superfamily regulators. Mol. Reprod. Dev. 84:626-637. https://doi.org/10 $.1002 / \mathrm{mrd} .22828$.

Kevenaar, M. E., M. F. Meerasahib, P. Kramer, B. M. N. Van De Lang-Born, F. H. De Jong, N. P. Groome, A. P. N. Themmen, and J. A. Visser. 2006. Serum anti-Mullerian hormone levels reflect the size of the primordial follicle pool in mice. Endocrinology 147:3228-3234. https://doi.org/10.1210/en.2005-1588.
Lawrence, M., W. Huber, H. Pagès, P. Aboyoun, M. Carlson, R. Gentleman, M. T. Morgan, and V. J. Carey. 2013. Software for computing and annotating genomic ranges. PLOS Comput. Biol. 9:e1003118. https://doi.org/10.1371/journal.pcbi.1003118.

Lee, K. B., A. Bettegowda, G. Wee, J. J. Ireland, and G. W. Smith. 2009. Molecular determinants of oocyte competence: Potential functional role for maternal (oocyte-derived) follistatin in promoting bovine early embryogenesis. Endocrinology 150:2463-2471. https://doi.org/10.1210/en.2008-1574.

Lourenço, D., R. Brauner, L. Lin, A. D. Perdigo, G. Weryha, M. Muresan, R. Boudjenah, K. M. Guerra-Junior, A. T. Maciel-Guerra, J. C. Achermann, and A. Bashamboo. 2009. Mutations in NR5A1 associated with ovarian insufficiency. N. Engl. J. Med. 360:1200. https://doi.org/10.1056/NEJMoa0806228.

Luo, X., Y. Ikeda, and K. L. Parker. 1994. A cell-specific nuclear receptor is essential for adrenal and gonadal development and sexual differentiation. Cell 77:481-490. https://doi.org/10.1016/0092 -8674(94)90211-9.

McAllister, J. M., R. S. Legro, B. P. Modi, and J. F. Strauss. 2015. Functional genomics of PCOS: From GWAS to molecular mechanisms. Trends Endocrinol. Metab. 26:118-124. https://doi.org/10 $.1016 / j . t e m .2014 .12 .004$.

Monniaux, D., S. Barbey, C. Rico, S. Fabre, Y. Gallard, and H. Larroque. 2010. Anti-Mullerian hormone: A predictive marker of embryo production in cattle? Reprod. Fertil. Dev. 22:1083-1091. https://doi.org/10.1071/RD09279.

Mossa, F., F. Carter, S. W. Walsh, D. A. Kenny, G. W. Smith, L. H Janet, T. B. Hildebrandt, P. Lonergan, J. J. Ireland, and A. C. O. Evans. 2013. Maternal undernutrition in cows impairs ovarian and cardiovascular systems in their offspring. Biol. Reprod. 88:92. https://doi.org/10.1095/biolreprod.112.107235.

Mossa, F., J. K. Folger, J. L. H. Ireland, G. W. Smith, P. Lonergan, A. C. O. Evans, and J. J. Ireland. 2010. Evidence that high variation in antral follicle count during follicular waves is linked to alterations in ovarian androgen production in cattle. Reproduction. https://doi.org/10.1530/REP-10-0214.

Muttukrishna, S., D. Tannetta, N. Groome, and I. Sargent. 2004. Activin and follistatin in female reproduction. Mol. Cell. Endocrinol. 225:45-56. https://doi.org/10.1016/j.mce.2004.02.012.

Newman, J. H., T. N. Holt, L. K. Hedges, B. Womack, S. S. Memon, E. D. Willers, L. Wheeler, J. A. Phillips 3rd, and R. Hamid. 2011. High-altitude pulmonary hypertension in cattle (brisket disease): Candidate genes and gene expression profiling of peripheral blood mononuclear cells. Pulm. Circ. 1:462-469. https://doi.org/10 $.4103 / 2045-8932.93545$.

O'Shea, L. C., J. Mehta, P. Lonergan, C. Hensey, and T. Fair. 2012. Developmental competence in oocytes and cumulus cells: Candidate genes and networks. Syst Biol Reprod Med 58:88-101. https://doi.org/10.3109/19396368.2012.656217.

Pangas, S. A., and A. Rajkovic. 2006. Transcriptional regulation of early oogenesis: In search of masters. Hum. Reprod. Update 12:6576. https://doi.org/10.1093/humupd/dmi033.

Patel, O. V., A. Bettegowda, J. J. Ireland, P. M. Coussens, P. Lonergan, and G. W. Smith. 2007. Functional genomics studies of oocyte competence: Evidence that reduced trascript abundance for follistatin is associated with poor developmental competence of bovine oocytes. Reproduction 133:95-106. https://doi.org/10 $.1530 /$ rep.1.01123.

Perry, J. R. B., G. McMahon, F. R. Day, S. M. Ring, S. M. Nelson, and D. A. Lawlor. 2016. Genome-wide association study identifies common and low-frequency variants at the AMH gene locus that strongly predict serum AMH levels in males. Hum. Mol. Genet. 25:382-388. https://doi.org/10.1093/hmg/ddv465.

Pigny, P., E. Merlen, Y. Robert, C. Cortet-Rudelli, C. Decanter, S. Jonard, and D. Dewailly. 2003. Elevated serum level of Anti-Mullerian hormone in patients with polycystic ovary syndrome: relationship to the ovarian follicle excess and to the follicular arrest. J. Clin. Endocrinol. Metab. 88:5957-5962. https://doi.org/10.1210/ jc.2003-030727. 
Ribeiro, E. S., R. S. Bisinotto, F. S. Lima, L. F. Greco, A. Morrison, A. Kumar, W. W. Thatcher, and J. E. P. Santos. 2014. Plasma anti-Müllerian hormone in adult dairy cows and associations with fertility. J. Dairy Sci. 97:6888-6900. https://doi.org/10.3168/jds .2014-7908

Self, S. G., and K.-Y. Liang. 1987. Asymptotic properties of maximum likelihood estimators and likelihood ratio tests under nonstandard conditions. J. Am. Stat. Assoc. 82:605-610.

Souza, A. H., P. D. Carvalho, A. E. Rozner, L. M. Vieira, K. S. Hackbart, R. W. Bender, A. R. Dresch, J. P. Verstegen, R. D. Shaver, and M. C. Wiltbank. 2015. Relationship between circulating antiMüllerian hormone $(\mathrm{AMH})$ and superovulatory response of highproducing dairy cows. J. Dairy Sci. 98:169-178. https://doi.org/10 .3168/jds.2014-8182.

Storey, J. D., and R. Tibshirani. 2003. Statistical significance for genomewide studies. Proc. Natl. Acad. Sci. USA 100:9440-9445. https://doi.org/10.1073/pnas.1530509100.

Tiftik, A. M., A. Kelimeler, and O. Kisti. 2016. Anti-Müllerian hormone $(\mathrm{AMH})$ in adults with polycystic ovary syndrome and pregnants. Ann. Eurasian Med. 4:65-70. https://doi.org/10.4328/ AEMED.92.

Triepels, R., L. Van den Heuvel, J. Loeffen, R. Smeets, F. Trijbels, and J. Smeitink. 1998. The nuclear-encoded human NADH:ubiquinone oxidoreductase NDUFA8 subunit: CDNA cloning, chromosomal localization, tissue distribution, and mutation detection in complex-I-deficient patients. Hum. Genet. 103:557-563. https://doi .org/10.1007/s004390050869.

Van Vleck, L. D. 1993. Selection Index and Introduction to Mixed Model Methods. CRC Press, Boca Raton, FL.

Veerkamp, R. F., H. A. Mulder, R. Thompson, and M. P. L. Calus. 2011. Genomic and pedigree-based genetic parameters for scarcely recorded traits when some animals are genotyped. J. Dairy Sci. 94:4189-4197. https://doi.org/10.3168/jds.2011-4223.

Watanabe, K., T. R. Clarke, A. H. Lane, X. Wang, and P. K. Donahoe. 2000. Endogenous expression of Mullerian inhibiting substance in early postnatal rat Sertoli cells requires multiple steroidogenic factor-1 and GATA-4-binding sites. Proc. Natl. Acad. Sci. USA 97:1624-1629. https://doi.org/10.1073/pnas.97.4.1624.

Welt, C. K., U. Styrkarsdottir, D. A. Ehrmann, G. Thorleifsson, G. Arason, J. A. Gudmundsson, C. Ober, R. L. Rosenfield, R. Saxena, U. Thorsteinsdottir, W. F. Crowley, and K. Stefansson. 2012. Variants in DENND1A are associated with polycystic ovary syndrome in women of European ancestry. J. Clin. Endocrinol. Metab. 97:E1342-1347. https://doi.org/10.1210/jc.2011-3478.

Wiggans, G. R., T. A. Cooper, P. M. VanRaden, C. P. Van Tassell, D. M. Bickhart, and T. S. Sonstegard. 2016. Increasing the number of single nucleotide polymorphisms used in genomic evaluation of dairy cattle. J. Dairy Sci. 99:4504-4511. https://doi.org/10.3168/ jds.2015-10456.

Wijayagunawardane, M. P. B., A. Miyamoto, Y. Taquahashi, C. Gabler, T. J. Acosta, M. Nishimura, G. Killian, and K. Sato. 2001. In vitro regulation of local secretion and contraction of the bovine oviduct: Stimulation by luteinizing hormone, endothelin-1 and prostaglandins, and inhibition by oxytocin. J. Endocrinol. 168:117-130. https://doi.org/10.1677/joe.0.1680117.

Woolliams, J. a., and C. Smith. 1988. The value of indicator traits in the genetic improvement of dairy cattle. Anim. Prod. 46:333-345. https://doi.org/10.1017/S0003356100018948.

Ying, S. Y. 1988. Inhibins, activins, and follistatins: Gonadal proteins modulating the secretion of follicle-stimulating hormone. Endocr. Rev. 9:267-293. https://doi.org/10.1210/edrv-9-2-267. 